\title{
EL FEMINISMO: MÁS ALLÁ DE UN DILEMA AJENO
}

\author{
SONIA REVERTER BAÑÓN ${ }^{1}$ \\ Universitat Jaume I
}

Recibido: 08/02/2010

Aceptado: 20/04/2010

\section{Resumen}

Este artículo reflexiona sobre la cuestión de si tiene sentido hoy hablar de dos feminismos: el feminismo de la igualdad y el feminismo de la diferencia. El debate que en los setenta y ochenta se desarrolló dentro de estas dos interpretaciones feministas ha perdido vigencia, pero lo que se defiende aquí es que son los frutos de tal debate los que nos permiten hoy avanzar hacia nuevos tipos de feminismo que puedan cumplir con la transformación de las sociedades hacia un mundo más feminista. Y ello significa, como siempre significó, dos cosas: un mundo con más igualdad y con más libertad. Los dos aspectos son parte de la preciosa herencia que nos dejó el debate feminista al que nos referimos. Lo que defiendo como feminista de hoy es que en ningún caso debemos sacrificar uno por el otro.

Palabras clave: feminismo de la igualdad, feminismo de la diferencia, identidad, diversidad, igualdad, libertad, olas del feminismo.

\begin{abstract}
This paper reflects on the question of whether it still makes sense to speak of two feminisms: feminism of equality and feminism of difference. The debate within these two feminist interpretations during the seventies and eighties is no longer as relevant, but I argue here that the fruits of that debate are what today enable us to move towards new types of feminism that can achieve societies' transformation towards a more feminist world. And this implies, as it always has done, two things: a world with more equality and more freedom. These two aspects are part of the valuable legacy we have
\end{abstract}

1. Profesora Titular de Filosofía, Departamento de Filosofía y Sociología. Miembro del Instituto Universitario de Estudios Feministas y de Género. Universidad Jaume I.

Feminismo/s 15, junio 2010, pp. 15-32 
inherited from that feminist debate. As a feminist of today, what I defend is that in no circumstances should one be sacrificed for the other.

Keywords: feminism of equality, feminism of difference, identity, diversity, equality, difference, freedom, feminist waves. 
La cuestión que nos ocupa en este volumen es valorar en qué medida sigue vigente, o tiene sentido hoy, hablar de dos feminismos: feminismo de la igualdad y feminismo de la diferencia. Sin duda es una pregunta importante para hacerla hoy, cuando hay cierta distancia con el momento más caliente del debate entre dos maneras diferentes de interpretar la teoría y praxis feminista, momento que podemos situar en las décadas de los setenta y los ochenta; y cuando además esta distancia coincide con nuevos tipos de discursos, posicionamientos y estrategias feministas que nos pueden hacer pensar que el debate que marcó a una generación de feministas o bien se ha superado, o simplemente se ha olvidado. Analizando el panorama de pensamiento y praxis de las mujeres que hoy piensan y hacen feminismo también cabría pensar, como desde los noventa se ha hecho en algunos ámbitos, que el feminismo ha muerto. Ello podría dar explicación a una nueva etiqueta que en los noventa empezó a utilizarse, y que es la de «postfeminismo».

A pensar en todo ello voy a dedicar este tiempo que aquí nos convoca.

\section{La politización de las agendas feministas en los setenta}

La primera referencia conocida que se hizo al concepto de «oleada» (wave en el original inglés) para referirse a la periodización del movimiento feminista fue hecha por la feminista Kate Millett, quien en 1971 declaró:

... that the first wave of feminism in the early twentieth century, which lost much of its force with the achievement of women's right to vote, was reborn as a second wave of feminist action in the early $1960 \mathrm{~s}^{2}$.

Precisamente esta afirmación de Millett se recogió en la revista que se nombró siguiendo las palabras que acabamos de citar, The second wave: A Magazine of the New Feminism. Es decir, la nueva ola se presenta como un «nuevo feminismo» respecto de la primera ola, la ola feminista que nació en el siglo XIX con el objetivo principal de luchar por el voto para las mujeres. En esta

2. The Second Wave: A Magazine of the New Feminism, 1971-1984. Editada por la organización «Female Liberation», de Boston. Hoy se encuentra en los Women's Movement Archives, de Cambridge Women's Center (Boston, Massachussets).

Feminismo/s 15, junio 2010, pp. 15-32 
misma revista se explica que Millett entendió que esa segunda y nueva oleada del feminismo se genera en la década de los 60, cuando las mujeres se dan cuenta de que el feminismo de finales del XIX y principios de siglo XX había perdido su fuerza después de conseguido el voto en muchos países en los que movimientos de mujeres se habían organizado para esa lucha.

En la época en que Millett habló de «segunda ola» su libro Sexual Politics (publicado en $1970^{3}$ ) se estaba convirtiendo en un libro clave no sólo para el feminismo, sino también para la teoría política y otras ciencias sociales ${ }^{4}$.

El impacto de este trabajo de Millett fue enorme $e^{5}$ y abrió una línea de pensamiento feminista tremendamente fecunda incluso hoy ${ }^{6}$. Andrea Dworkin

3. El libro fue la tesis doctoral que Millett presentó en la Columbia University y que fue publicado originalmente en Nueva York por Doubleday and Co. En aquella época y debido a la exitosa venta del libro Millett ganó 30.000 dólares, que utilizó para establecer la «Women's Art Colony Farm» para escritoras y artistas visuales que aún sigue abierta y que es donde reside habitualmente Kate Millett. En la actualidad esta primera edición de Sexual Politics forma parte de los tesoros de la biblioteca de la Columbia University y de la exhibición que a propósito del 250 aniversario de esta universidad se organizó en el 2004 (Jewels in her Crown: Treasures of Columbia University Libraries Special Collection). Pese a ello y como contraste Kate Millett escribe unos años antes de esta exhibición, en 1988: «No puedo conseguir empleo. No puedo ganar dinero. Excepto vendiendo árboles de Navidad, uno por uno. No puedo enseñar y no tengo nada más que ser granjera. Y cuando físicamente ya no pueda, ¿qué haré entonces? Nada de lo que escribo ahora tiene prospecto de verse impreso. De todos mis supuestos logros, no tengo ninguna habilidad vendible» (en «iSomos las mujeres incapaces de honrar nuestra propia historia?», en http://www.jornada.unam.mx/1999/02/01/kate-Millett.htm. Se trata de la traducción al castellano por Amparo Jiménez de un artículo publicado en The Guardian, Londres, junio, 1988). Encuentro que esta afirmación de Millett es significativa en cuanto nos da la medida del desinterés social por el feminismo a partir de los noventa y que algunos denominaron «muerte del feminismo», como he comentado más arriba.

4. Millett, Kate. Política sexual. Madrid, Cátedra-Instituto de la Mujer. Colección Feminismos, 1995.

5. La división comercial de la editorial que publicó este libro, Doubleday, dijo que Sexual Politics fue uno de los diez libros más importantes que había publicado, y lo incluyó en la antología que hicieron en 1987 para celebrar los cien años de existencia de la editorial. Aún así se negaron a reeditarlo o siquiera a reimprimirlo, aduciendo que el «clima actual» no era el apropiado.

6. Este libro de Millett es considerado como uno de los fundamentales del feminismo de la segunda ola, que además tiene la cualidad de tener un mensaje vigente para el siglo XXI. Sheila Jeffreys piensa que esta cualidad no la comparten otros libros importantes de la época de los setenta, como puede ser el libro de Sulamith Firestone, Dialectics of Sex, publicado también en 1970, el cual Jeffreys acertadamente cree que ha perdido su capacidad para inspirar la agenda feminista del siglo XXI. Véase la conferencia de Sheila Jeffreys sobre Kate Millett en la Universidad de Melbourne en marzo de 2009, en <www.themonthly.com.au/key-thinkers-sheila-jeffreys-kate-Millettt-1564>, consultado el 2-12-2009. 
dijo de su autora que «el mundo estaba dormido y Kate Millett lo despertó ${ }^{7}$. $\mathrm{Su}$ impacto fue tal que en el mes de agosto de ese mismo año en la portada de la revista Time aparecía un dibujo del rostro de Kate Millett con el título de su libro. El libro de Millett explicaba de manera contundente y clara cómo el sexo es una cuestión política, y cómo la política usa de estrategias de represión del sexo. Una de las conclusiones clave de las tesis de este libro para el feminismo fue que ha de ser también con la política que establezcamos estrategias de liberación. Fue esta tesis la que llevó a lo que se convirtió en un eslogan de la época: «lo personal es político». De alguna manera Sexual Politics proveyó de una ideología para el asalto al patriarcado; un asalto entendido no sólo como una lucha por conseguir el voto u otros derechos del mundo moderno liberal, sino como una compleja estrategia para desestabilizar y subvertir los pilares de la interpretación y la significación de la realidad y la experiencia humana. Esta compleja estrategia se desveló pronto como una tarea masiva y de muy largo recorrido para desactivar tópicos, deconstruir valores y resignificar conceptos. Podemos decir que esta idea de la politización de lo personal, no sólo defendida entonces por Kate Millett, marcó el punto de partida del feminismo de la segunda ola.

La segunda ola del feminismo fue en realidad un segundo momento en la lucha por los derechos de las mujeres, yendo un paso más allá de los conseguidos por las feministas de la primera ola. Para ello, sin embargo, no bastaba simplemente con sumar derechos en las proclamas feministas, sino indagar de manera penetrante en las estructuras de la dominación para entender cómo se construye la subyugación de las mujeres, la construcción de la mujer como «alteridad absoluta», como poco más de dos décadas antes nos dijo Simone de Beauvoir en El segundo sexo. Es esa praxis de incisivo desvelamiento de esa estructura la que lleva a comprender con claridad que el patriarcado es un armazón compacto, cerrado y milimetrado, con pocas rendijas y que para desmontarlo hará falta algo más que leyes y derechos. La complejidad de la lucha, sumado al momento histórico, social, político y económico, hizo que el movimiento feminista, sobre todo en Estados Unidos, invocara a muchas mujeres (y algunos hombres) y se convirtiera en pocos años en un movimiento muy visible y con un significativo poder de convocatoria.

La mayoría de las mujeres que se movilizaron por la agenda de lucha feminista estaban o sensibilizadas o directamente implicadas en los movimientos de derechos civiles. Y es que el feminismo de las décadas de los 60, 70 y 80

7. Andrea Dworkin dijo: «The world was sleeping and Kate Millett woke it up», en un artículo de opinión titulado "Great thinkers of our time- Kate Millett», publicado en la Revista New Statesman, del 14 de Julio de 2003. 
no se aparta de la lucha por los derechos. Su agenda básica, aunque más compleja que la lucha por derechos que inició la primera ola, sigue vinculada a sumar derechos para las mujeres. Sin embargo hay matices de diferencia entre una ola y otra en este aspecto: en la segunda ola no se trata tanto de sumar mujeres a los derechos ya existentes para los varones, sino de sumar derechos para las mujeres. Esta nueva agenda se entendió en una doble tarea: había que conquistar derechos que integrasen a las mujeres y a los hombres desde una concepción más amplia, más inclusiva y no androcéntrica de la ley y los derechos; y también había que crear derechos nuevos que dieran respuesta a necesidades y deseos de las mujeres.

Podemos decir que, en general, el feminismo de la igualdad se volcó principalmente en la primera tarea; mientras que el feminismo de la diferencia se concentró en la segunda. Sin embargo, y a pesar de ello, sería simplista reducir las agendas de estas dos interpretaciones feministas a una u otra de esas dos vías.

\section{2. ¿Qué es una mujer? dilemas y paradojas}

La primera oleada, cuyo inicio se suele situar en 1848, en la Convención americana de Seneca Falls, centró sus discursos y su lucha en la consecución de los derechos de las mujeres. Pero ¿qué derechos? En la idea de la época las mujeres lo expresaban pidiendo «los mismos derechos concedidos a los hombres $»^{8}$. Con esta proclama básicamente las mujeres se referían al territorio legal que la tradición occidental, y especialmente la ilustrada y liberal, habían delimitado al elaborar derechos y privilegios de los individuos varones. Las mujeres se centraron en la conquista de tres pilares de ese territorio legal: el voto, el control sobre la propiedad y la persona, y la entrada a las profesiones y las jerarquías institucionales ${ }^{9}$.

Podemos decir que el concepto básico del feminismo, desde sus orígenes, es el de igualdad. En concreto el feminismo ha tenido como principio fundacional la idea de que hombres y mujeres cuentan con las mismas capacidades esenciales y que por tanto ello debe llevar a poder disfrutar de las mismas oportunidades. Es cierto que también el feminismo desde finales del siglo XIX, con la lucha organizada de manera colectiva por las mujeres para pedir el voto, acepta las diferencias entre hombres y mujeres en algunos ámbitos

8. En los documentos de Seneca Falls y otros de este periodo la expresión era «rights equal to those granted men».

9. Véase OFFEN, Karen. «Defining feminism: a comparative historical approach». En Gisela Bock y Susan James, eds., Beyond Equality and Difference. London, Routledge, 1992, pp. 79-88. 
pero lucha porque esas diferencias sean reconocidas en igual valor a aquellas diferencias de los hombres. Por ello también la aceptación de diferencias se hace y se exige dentro de un marco conceptual que tiene a la igualdad como concepto rector. La tensión entre los diferentes feminismos se genera cuando hay que explicar en qué consisten esas diferencias y qué alcance tiene el marco de igualdad que vaya a servir de trasfondo para la interpretación feminista del mundo. Y este será de hecho uno de los temas prioritarios de la agenda de la segunda ola.

La proclama de «lo personal es político» y la politización entera del discurso de la igualdad y las diferencias entre mujeres y hombres ampliaron la agenda feminista llevándola a la necesidad de indagar aspectos tan básicos de la realidad social, política y cultural, que se habían tomado hasta entonces como simples verdades absolutas. Ello llevó a la cuestión posiblemente más básica de todas: ¿qué es una mujer?

En 1851 Sojourner Truth preguntó en un discurso en la Convención de Mujeres celebrada en Ohio: «Ain't I a Woman ${ }^{10}$. Con este interrogante Truth preguntaba por qué si una mujer puede hacer lo mismo que un hombre no es considerada igual y no tiene los mismos derechos. Es decir, Truth interpreta, igual que otras feministas de la época, que es un marco de igualdad universal el que ha de estructurar las relaciones entre humanos, tanto hombres como mujeres, tanto blancas como negras; y eso es lo que está pidiendo, que se cumpla esa igualdad universal. Casi cien años después, en 1949, Simone de Beauvoir se pregunta en El segundo sexo qué es una mujer. En Beauvoir la pregunta no es un cuestionamiento al incumplimiento de la igualdad universal, sino que es un interrogante de por qué la mujer es construida como inferior, como dominada, como segundo sexo, como alteridad absoluta. Beauvoir va más allá de esa aparente estructura de igualdad que proclaman los derechos humanos y el discurso universal de la modernidad; ella va a escarbar con su libro la tierra que sostiene los pilares de la desigualdad entre hombres y mujeres. Y con ello va a cambiar radicalmente la manera como entendemos la

10. El discurso se hizo en la Women's Convention, en Akron, Ohio el 29 de Mayo de 1851, y ha sido reproducido en muchos libros, revistas y páginas web. Hay una controversia referente a cuál es la trascripción legítima o más adecuada de aquel discurso. La primera versión impresa fue la del editor Marius Robinson, en la cual no se encuentra la frase «Ain't I a woman». La segunda versión, que contiene cuatro veces tal frase, es la de Frances Dana Barker Gage que, aunque es la versión estándar que normalmente se cita, algunas interpretaciones dudan que sea enteramente original.

Una de las referencias en las que se puede ver esta última versión: TRUTH, Sojourner. «Ain't I a Woman». Feminist Theory: A Reader. 2nd Ed. Wendy Kolmar y Frances Bartowski (eds.). New York, McGraw-Hill, 2005, pp. 79.

Feminismo/s 15, junio 2010, pp. 15-32 
pregunta de qué es una mujer. Si en Sojourner Truth esta pregunta implicaba asumir que una mujer es un ser humano como un hombre, es decir con los mismos derechos; en Simone de Beauvoir implica abrir la concepción de género y ver las maneras como nos hacemos lo que somos. En este sentido, en Beauvoir la pregunta qué es una mujer se resuelve con otra pregunta: ¿cómo se hace una mujer?

Desde esta nueva cuestión el feminismo se sitúa en las profundidades de la filosofía constructivista y en los discursos que empiezan a interrogar el conjunto de pilares epistemológicos que se habían creído naturales, verdaderos y universales ${ }^{11}$. Beauvoir va a ser un paso determinante en la deconstrucción feminista del discurso universalista de los derechos: no sólo el problema es que no se cumpla, sino que el sexismo de la sociedad determina que sólo el hombre sea lo universal, mientras que la mujer es lo particular. El hombre es el sujeto legitimado, la mujer es lo otro, la alteridad absoluta. La teórica Nancy Cott ${ }^{12}$ entiende que este aspecto es el que marca la diferencia entre el feminismo moderno de la segunda ola y los feminismos anteriores. En el feminismo de la primera ola la mujer se entiende como una entidad universal; en el feminismo de la segunda ola explicar el sujeto conlleva necesariamente volver la mirada a la individualidad y a la diversidad. La conciencia de esta gran diversidad individual y también de comunidades y grupos identitarios hará necesario entender mejor las diferencias. Esta conciencia de diversidad llevó a plantear escenarios diferentes de lucha política del movimiento feminista; precisamente porque «lo personal es político» había que rastrear bien debajo del gran sistema de dominación que resultaba ser el patriarcado todas las diferencias en el hecho personal, y especialmente aquellas diferencias que el sistema convertía en desigualdades. Las décadas de apogeo de la segunda ola feminista fueron así un momento de diversificación de agendas y de explosión de reivindicaciones. Muchas de ellas se agruparon en dos interpretaciones, que son las conocidas como feminismo de la igualdad y feminismo de la diferencia.

El debate entre una interpretación y otra, aún siendo novedoso, tenía, como casi siempre, sus orígenes en algunas feministas anteriores. En este sentido, y como algunas voces han señalado, hay que responsabilizar al relato de la historia del feminismo el hecho de que hayan visibilizado unas historias o proclamas y no otras. Así, contar la periodización como se ha contado es en gran parte la responsable de que luego se haya producido esa concentración

11. Cf. para esta cuestión MoI, Toril. What is a Woman? And Other Essays. Oxford University Press, 2000.

12. CotT, Nancy F. The Grounding of Modern Feminism. New Haven, Yale University Press, 1987. 
del debate del tema igualdad-diferencia en la segunda ola. En realidad podemos decir, como cada vez más testimonios históricos nos demuestran, que en el siglo XIX ya estaba sobre la mesa ese debate ${ }^{13}$. La diferencia es que en el siglo XX ese debate llegó a ocupar el centro mismo de la mesa. Hoy sigue estando sobre la mesa, pero la mesa está no sólo mucho más llena de debates y controversias, sino que alrededor hay muchas más comensales.

Como ejemplo de la controversia igualdad-diferencia conviene citar a la pensadora británica Mary Wollstonecraft, quien es considerada la autora del primer libro de teoría feminista, titulado Vindicación de los derechos de la mujer y publicado en Inglaterra en 1792. En este libro Wollstonecraft propuso precisamente, al calor de las flamas de la Revolución Francesa, extender los derechos de la ciudadanía a las mujeres. Ahora bien, esta autora, a diferencia de otras feministas de la época, reclamaba no una mera extensión de los derechos de los hombres a las mujeres, sino un reconocimiento de las diferencias de las mujeres y la inclusión de estas en la carta de derechos. Así, por ejemplo reivindicó que el trabajo de muchas mujeres como esposas/madres era un trabajo diferente, pero equivalente, al de los hombres fuera del hogar; y que por tanto los dos debían ser reconocidos como «trabajo productivo». La sociedad debía reconocer, afirmaba, el valor de ambos como parte de la ciudadanía, y por ello también las mujeres han de ser consideradas ciudadanas de pleno derecho ${ }^{14}$.

Carole Pateman ${ }^{15}$, autora feminista contemporánea, cree que la propuesta de Wollstonecraft nos lleva de pleno al dilema de la ciudadanía diferenciada y a la pregunta acerca de qué significa ser ciudadana en igualdad. Según el análisis de Pateman hay dos caminos por los que las mujeres han reclamado

13. Cada vez más aparecen estudios históricos sobre el feminismo que evidencian la existencia de muchas voces de mujeres de la época del siglo XIX que no se dejan atrapar en ese programa de «búsqueda de derechos individuales iguales a los hombres». Encontramos testimonios de mujeres, sobre todo fuera de la tradición angloamericana, que es la que ha servido principalmente para contar la historia del feminismo, que no hablaban en sus reivindicaciones en clave de «derechos», y también de algunas que si lo hacían usaron la fórmula de «derechos de las mujeres», y no «derechos iguales a los de los hombres». Véase para este tema los valiosos trabajos de Karen Offen: OfFEN, Karen. «Defining feminism: a comparative historical approach», en Gisela Bock y Susan James (eds.), Beyond Equality and Difference. London, Routledge, 1992, pp. 79-88; y OFFEN, Karen. «Feminism and sexual difference in historical perspective». En Deborah Rhode, (ed.), Theoretial Perspectives on Sexual Difference. New Haven, Conn., Yale University Press, 1990, pp. 13-20.

14. Wollstonecraft, Mary. Vindicación de los derechos de la mujer. Madrid, Cátedra-Instituto de la Mujer, 1994 (traducción de Carmen Martínez Gimeno y edición de Isabel Burdiel).

15. Pateman, Carole. The disorder of Women. Cambridge, Polity Press, 1989.

Feminismo/s 15, junio 2010, pp. 15-32 
y reclaman actualmente la ciudadanía y los derechos a ella asociados: a través de la lucha por la igualdad, la extensión de los derechos de los ciudadanos a las mujeres; y, a través de la lucha por la diferencia, derechos distintos a los de los hombres; puesto que las habilidades, capacidades, intereses y necesidades de las mujeres son diferentes. Pateman señaló, precisamente, cómo estas dos vías para reclamar la ciudadanía resultaban un auténtico dilema, al que acuñó con el nombre de «dilema de Wollstonecraft». Según este ambas vías de ciudadanía tienen consecuencias negativas para las mujeres: «El dilema es que los dos caminos hacia la ciudadanía que las mujeres han tomado son incompatibles dentro de los límites del estado patriarcal, y dentro de ese contexto resultan imposibles» ${ }^{16}$.

En el caso del dilema entre igualdad y diferencia que puso sobre la mesa Wollstonecraft, y que ahora Pateman interpreta, la cuestión, y el debate, es la diferencia entre los sexos. Es decir en qué medida hombres y mujeres han de tener reconocidas diferencias de sexo para que la igualdad sea plena. Este fue también en gran parte el debate que las feministas de la segunda ola tuvieron. Sin embargo, en el debate del siglo XX se introducen algunos elementos que provocarán en unas décadas una nueva deriva del feminismo, a la que luego volveremos. La idea central del dilema de Wollstonecraft era entender la igualdad de manera diferente a homogeneidad, y a la vez entender la diferencia entre hombres y mujeres como una diferencia que pudiera generar derecho; algo en rotunda contradicción con los pilares del estado liberal patriarcal, como nos dice Pateman.

Este dilema sin aparente solución dentro de ese estado liberal es el que formula también Joan Scott ${ }^{17}$ como la paradoja del pensamiento feminista y que ella llama "problema de la diferencia». Lo que nos cuenta Scott está inspirado en lo que dijo en su momento Olimpia de Gouges en la época de la Revolución Francesa cuando se le preguntó qué podían ofrecer las mujeres: «sólo tenemos paradojas que ofrecer...». Scott analiza esa paradoja sustancial de la lucha feminista: reclamar la igualdad a partir de afirmar la diferencia. En el transcurso de su análisis, Scott pone en evidencia que la paradoja no tiene su origen en el feminismo, sino que es fundamental y constitutiva del pensamiento liberal universal, al conformar un individualismo abstracto que sólo se hace cuerpo en el hombre (varón). Esta es realmente la paradoja original que está a la base de las demandas igualitaristas del feminismo, y de otros

16. Ibíd., p.196.

17. SCOTT, Joan. Only Paradoxes to Offer: French Feminists and the Rights of Man. Cambridge, Harvard University Press, 1996.

Feminismo/s 15, junio 2010, pp. 15-32 
movimientos de lucha por la inclusión, al partir del esquema de pensamiento liberal.

Es precisamente este esquema el que podemos entender que ha obligado a plantear la igualdad y la diferencia en una suerte de dilema o paradoja irresolubles. Por ello mismo, porque nos enfrentamos con esa paradoja liberal del patriarcado (o paradoja patriarcal del liberalismo) los largos debates de las feministas de la segunda ola sobre igualdad y/o diferencia no han sido improductivos. Muy al contrario, han posibilitado problematizar todos los conceptos importantes para llegar a entender el hecho de la dominación de las mujeres, y nos han obligado a ver y establecer agendas múltiples de lucha política que nos permitiera avanzar en muy diversos frentes.

Toda la vasta producción teórica que el feminismo produjo en las décadas de los 60, 70 y 80 tiene su origen en la que parece esa irresoluble paradoja. Y ello ha permitido derribar muchas barreras, repensar muchos tópicos, e incluso reordenar el conocimiento ${ }^{18}$. Como nos cuenta Beverly Skeggs «las feministas reinscribieron el objeto y sujeto de la cultura, re-imaginaron la labor del poder y expusieron los mecanismos por los que se obtiene el conocimiento» ${ }^{19}$.

En definitiva, el feminismo y la investigación feminista que se desarrollaron a partir de los 70 tuvieron la fuerza y el impacto suficiente para hacer pensar el sujeto de otra manera, pudiendo empezar así a desmantelar el nudo principal que ataba la construcción entera del conocimiento patriarcal en un sujeto universal que no admitía diferencias. Tanto el feminismo de la igualdad como el feminismo de la diferencia luchaban precisamente por derrocar ese dilema que el sistema liberal propone al obligar a elegir entre la igualdad enmarcada en un modelo de sujeto universal recortado sobre el perfil del varón blanco occidental; y la libertad de reclamar una diferencia que precisamente el sistema establece que es la que te deja fuera, la que no cuenta, y la que te convierte en alteridad absoluta. Interpretar, como se ha interpretado, que los feminismos de la segunda ola se posicionan en una elección u otra de esos dos polos creo que es erróneo e injusto con la mayoría de las feministas de esa época. Esa visión dicotómica, en blanco y negro, de la segunda ola ha sido la visión que el mismo sistema liberal ha organizado desde las opciones que él mismo estructura. Encapsular las praxis y teorías feministas de las décadas de los 60, 70 y 80 en esas etiquetas es reducir la herencia del feminismo a

18. Véase REVERTER BAÑÓN, Sonia. «El ruido de la teoría feminista». Cuadernos KÒRE, n.1 (2009), pp. 53-68.

19. SKEGGS, Beverly. «The dirty history of feminism and sociology: or the war of conceptual attrition». The Sociological Review, 56:4 (2008), pp. 670-690. La cita es mi traducción del original en p. 628.

Feminismo/s 15, junio 2010, pp. 15-32 
los caminos trazados por el mismo sistema patriarcal que se quiere derrocar. Estudiar atentamente los escritos de esas décadas ${ }^{20}$, como en gran parte de centros y seminarios de estudios de mujeres están haciendo hoy, nos lleva a recuperar la historia reciente del feminismo en clave no dicotómica.

\section{Tercera ola: ¿qué quiere una mujer?}

Lo que hemos aprendido del debate de los feminismos de la segunda ola nos llega a las feministas de final de siglo como una «herencia sin testamento», como nos dice la pensadora francesa François Collin ${ }^{21}$. Es decir, un legado abierto que interpela a quien lo quiera abordar para que tome la iniciativa no sólo de transmitir, sino de reinterpretar, de llevarlo adelante, de darle vida para que no sea solamente un pasado, sino un presente y un futuro que otras y otros recibirán de nuevo como herencia sin testamento. Es una herencia, por tanto, que no deja condiciones; porque el feminismo no es una institución ni un monumento, es un espíritu de lucha. Y de lucha ¿para qué?, podemos preguntar. Básicamente de lucha por repensar un mundo más justo, y ello, a su vez, significará llevar adelante una pluralidad de luchas. Así, las mujeres de hoy son herederas de un futuro posible para el cual no hay un modelo, son herederas de un trabajo de transformación comenzado por generaciones de mujeres que previeron y soñaron con ese futuro. En palabras de Collin:

Porque si, en expresión de Arendt, «la tradición se ha roto», esto es así paradigmáticamente para las mujeres, las cuales tienen hoy que «juzgar» $\mathrm{y}$ «decidir», al margen de todo modelo y de toda norma, en la medida en que su herencia no ha sido precedida por ningún «testamento», por emplear la expresión que ella misma toma de René Char ${ }^{22}$.

En esta herencia las nuevas generaciones han de reinterpretar básicamente aquella pregunta que tantas feministas se han planteado antes: ¿Qué es ser una mujer? El debate nos ha llevado en los noventa a pensar en profundidad la identidad, y con ello los conceptos de igualdad y diferencia; y hemos entendido que eso es también lo que se hizo en el debate de la segunda ola. Los conceptos de igualdad y diferencia se empiezan ya en los setenta a entender

20. Uno de los trabajos que realiza esta tarea y que recomiendo es el de Linda ZERILLI El feminismo y el abismo de la libertad, Buenos Aires, Fondo de Cultura Económica, 2008, Traducido por Teresa Arijón (original en lengua inglesa de 2005).

21. Collin, Françoise. «Una herencia sin testamento». En VV.AA. Feminismos fin de siglo. Una herencia sin testamento, especial Revista Fempress, Chile 1999. La expresión del título la ha tomado la autora de Hannah Arendt, quien a su vez la toma del poeta René Char.

22. Collin, François. Praxis de la diferencia. Liberación y libertad. Barcelona, Icaria, 2006, p. 112. 
de manera diferente, conteniendo más matices y complicando por tanto, aunque también enriqueciendo, el debate que de alguna manera de Gouge con su paradoja o Wollstonecraft con su dilema iniciaron. No hay un salto temático entre lo que conocemos como segunda ola y lo que se denomina tercera ola; lo que hay es más experiencia y más conocimiento (y sabiduría) de lo que un sujeto es y de las circunstancias en las que puede ser. Hay una red más densa de conceptos y de experiencias; hay un legado más rico y más diverso, y un camino más sólido a la vez que abierto. Sabemos que no hay una única igualdad y no hay una única diferencia; y por tanto tampoco hay una única identidad. ¿Cómo está desarrollando el feminismo hoy, en el siglo XXI, esta herencia?

La deriva feminista en los noventa, la que se ha dado en llamar «tercera ola», está implicada en dos circunstancias que van a suponer probablemente los retos más importantes, no sólo para el feminismo, sino para cualquier movimiento de transformación social:

-la deconstrucción del sujeto y el replanteamiento de la identidad como algo inestable.

-la despolitización de la agenda feminista por causas de diversa índole (capitalismo narcisista, feminismo de estado, clientelismo de los movimientos sociales, irrupción masiva de las tecnologías de la información y la comunicación).

La teoría feminista reconoce que la misma conciencia que nos ha llevado a entender los intersticios de las relaciones de poder que se conforman en las estructuras del patriarcado nos ha llevado a la conciencia de la diferencia. Se hace así necesario entender que si bien las mujeres son subyugadas, no todas lo son de la misma manera ni bajo las mismas circunstancias. Razones de clase, raza, sexualidad, etnicidad, religión, ideología, profesión, etc., complican el panorama de las relaciones de poder y dominación. Y por ello cada vez se hace más difícil hablar de experiencia genérica de las mujeres. Y estos serán precisamente los aspectos que han abierto esa nueva etapa en el feminismo que llamamos «tercera ola».

El reconocimiento paulatino, dentro de los diferentes feminismos de la segunda ola, de la gran diversidad que representan las mujeres es la clave para poder interpretar la gran diversidad de feminismos que en los noventa aparecen y que van a reprochar al feminismo de la segunda ola (en general tanto al de la igualdad como al de la diferencia) el haber partido de la asunción acrítica de un sujeto mujer unificado. Sin embargo, creo que esta crítica es injustificada, en el sentido en que ese paso fue necesario para andar el camino feminista a la vez que desandar el del patriarcado. Fueron los debates sobre unas feministas y otras en la segunda ola, intentando explicar qué es y cómo 
se hace una mujer, las que abrieron la posibilidad de entender que hay muchas y diversas maneras de responder a esa pregunta, y que nadie que no tome en cuenta la multiplicidad de variables puede dar por cerrada la pregunta.

Sería un error interpretar el final de la época del debate igualdad/diferencia en los términos en que se establecieron en los setenta como el final de feminismo, como en algunos ámbitos se interpretó en los noventa. Hacer eso significaría equivocar el feminismo y, por usar la metáfora de François Collin, comprenderlo como un testamento.

El concepto de género, el gran legado del feminismo de los setenta que arranca originalmente con la idea principal de El segundo sexo de Simone de Beauvoir, implicó que la concepción de construcción del sujeto asociada a él rompiera con la posibilidad de un sujeto estable y de identidad fija. Podemos decir que este nuevo debate es el centro de la tercera ola del feminismo, cuyo reto importante es tratar de dilucidar cómo seguir hablando de feminismo como movimiento social sin un sujeto que conforme el objetivo de las luchas y agendas de tal movimiento. La falta de una respuesta adecuada que cierre este dilema ha llevado a lo largo de la década de los 90 a proclamar de una manera u otra el «fin del feminismo $»^{23}$ o el comienzo de la era «postfeminista». Sin embargo, no creo que estemos ni ante uno ni ante el otro. Las luchas feministas siguen en plena vigencia; y la comprensión hoy del fenómeno de la dominación de las mujeres es mucho mayor de lo que jamás fue, no sólo entre los grupos de mujeres que normalmente trabajan en agendas feministas, sino entre la gran masa de la población en las diferentes sociedades del planeta. Las estrategias de lucha hoy son más efectivas, precisamente por ser más variadas y adaptadas a la problemática real de dominación de las mujeres en situaciones concretas. Esta realidad vuelve absurda la posibilidad de hablar de fin del feminismo; pero también, por todo lo que queda para llegar a un mundo con igualdad y respeto a las diferencias, se vuelve ridículo hablar de postfeminismo. Quien haya equivocado la tercera ola feminista con uno o con otro creo que se encuentra lejos de comprender en profundidad los feminismos, de ayer, de hoy, y tal vez de mañana.

¿Cómo traducimos para la agenda feminista la desaparición de un sujeto unificado? Para algunas voces críticas, de fuera del feminismo, se traduce en la imposibilidad de continuar la lucha política, puesto que ya no hay un sujeto mujeres, como sujeto de proclama de una agenda unificada. La estrategia es entonces simplemente dejar actuar y evolucionar la completa igualdad

23. Uno de los títulos que mejor refleja esto es el libro de Hoff SOMMERS, Christina. Who Stole Feminism? How Women Have Betrayed Women. Nueva York, Simon and Schuster, 1995. 
legal entre todos los humanos; algo ya encaminado por la misma lógica del progreso histórico. Es decir, según esta postura no hay que hacer nada, pues la misma lógica del sistema liberal y de mercado hará que, para sus propios intereses, evolucione la completa igualdad. El feminismo simplemente ya no es necesario. Y eso, interpretan, es una buena noticia.

Para otras voces críticas, de dentro del feminismo, la falta de ese sujeto mujeres lleva con cierta melancolía a tener que proclamar el fin de la lucha colectiva que el feminismo supuso. La multiplicidad de las realidades y de las agendas parece necesitar de una variación tan grande de lo que algunas llaman «micro-políticas» que la etiqueta de "política feminista» deja de tener sentido para convertirse en un universal más, tan vacuo como han demostrado ser los demás universales.

Esta última crítica ha sido objeto de encendidos debates entre las mismas feministas que se han acusado unas a otras de la responsabilidad de la desaparición de la categoría «mujeres» y del peligro del feminismo de desaparecer con ella. Las teóricas de la tercera ola, herederas, como hemos visto de un largo y falso debate entre el feminismo de la igualdad y el de la diferencia solventaron el dilema de la diferencia eliminando el sujeto mujeres.

Esta parece ser la acusación de las teóricas de la segunda ola a las de la tercera. Sin embargo, justo es decir, que las teóricas de la segunda ola mantuvieron, en cierto sentido, un debate largo (aunque no creo que podamos calificarlo ni de estéril ni de vacuo conceptualmente hablando), sobre el concepto mujer, que supuso en parte una buena dosis del caldo de cultivo de la resolución posterior de «muerte del sujeto» para el feminismo. En ningún caso esto es una acusación a esos largos debates, cuyo centro neurálgico se conoce como el debate entre feminismo de la igualdad y feminismo de la diferencia, sino que más bien lo que argumento es que es justamente la misma riqueza conceptual del feminismo y su carácter crítico el que ha promovido debates, disensiones y paradojas (como el trabajo de Joan Scott denomina ${ }^{24}$ ) y la que ha provocado una deriva teórica de permanente crisis. Este aspecto creo que es crucial para entender la teoría feminista no como una doctrina adherida a un feminismo definido sólo como un movimiento social con una agenda concreta y limitada (y excluyente), sino como una filosofía conceptualmente competente, y sobre todo, abierta, crítica y alejada de cualquier ortodoxia.

Una de las pensadoras clave para entender la deriva teórica del feminismo en los noventa es la norteamericana Judith Butler, quien con su obra ha ayudado a la tarea de la teoría feminista de seguir el camino de descentrar

24. SCOTT, Joan. Only Paradoxes to Offer: French Feminists and the Rights of Man. Op. cit.

Feminismo/s 15, junio 2010, pp. 15-32 
el sujeto, poner en riesgo sus certidumbres epistemológicas y exponer sus fracturas. Sin embargo, ¿por qué esto ha de interpretarse, como a veces se ha hecho, como la desaparición de la agenda feminista? Como la misma Butler ha reconocido, en definitiva «sigue siendo necesario y positivo hablar de derechos universales o de participación política como algo que debe ser universalmente inclusivo ${ }^{25}$. Por ello la autora reconoce que pese a las críticas a la Modernidad no podemos acabar de deshacernos de ella:

Lo importante es que todavía estamos en el proceso de articular cuáles deben ser las condiciones de emancipación cultural y de igualdad. Esto no es ni mucho menos lo mismo que decir que el proyecto de la Modernidad está inacabado, porque lo que estoy diciendo es que el proyecto de la Modernidad es inacabable y que no está claro, puesto que se desplaza; por eso es apropiado en varios contextos y por varias razones, que todavía podamos hablar de 'Modernidad' como tema ${ }^{26}$.

El feminismo ya no es la lucha por la situación de un grupo con una misma identidad, sino por desestabilizar las formas de subordinación. Su objetivo no es salvar una identidad (la de ser mujer), sino precisamente transgredir las estructuras de ordenación y adjudicación de identidades. En la nueva agenda feminista se hace necesaria la tarea de reordenar lo simbólico, pues es el andamio de las estructuras identitarias del patriarcado. El feminismo sigue siendo necesario, precisamente para enseñar a transgredir, para educar en la resistencia a la dominación. Y por ello mismo el feminismo es básicamente una lucha política posible y necesaria, una praxis transformativa. La tarea de una teoría feminista hoy es aclarar en qué condiciones esta praxis es posible.

En la época de crisis de la identidad y la completa inmersión en el construccionismo, no sólo del género sino también hoy del sexo, la pregunta que a las feministas interesa ya no es tanto qué es una mujer sino qué quiere una mujer (y una no por todas, sino por una misma). Responder a esto nos abre las puertas a la interrogación por las situaciones en que viven las mujeres hoy; y ello requerirá, no anular la agenda feminista por falta de un sujeto unificado; sino muy al contrario, ampliarla y diversificarla. Para la tercera ola del feminismo este es su reto más importante, y sabemos que no es fácil estando como estamos en un momento de crisis de lo político en manos de lo económico.

25. BUTLER, Judith. «La cuestión de la transformación social». En Judith Butler, Elisabeth Beck-Gernsheim y Lídia Puigvert, Mujeres y transformaciones sociales. Barcelona, El Roure, 2001, p. 88.

26. Ibid., pp. 88-89. 
El pasado año 2009 los días 5, 6 y 7 de diciembre se realizaron en Granada las Jornadas Feministas Estatales, que celebraron sus 30 años de vida. Todos los medios de comunicación reflejaron en sus crónicas la diversidad de mujeres que se congregaron allí, más de cuatro mil, de todas las edades, todas las ideologías, todas las profesiones, todas las clases, todas las sexualidades... Algunas de las convocadas habían participado en las Primeras Jornadas, que se celebraron en 1979. Una de ellas es Empar Pineda, una conocida feminista, quien en los años setenta y ochenta se situó abiertamente a favor de un feminismo de la igualdad y contra un feminismo de la diferencia «carente de $\operatorname{argumentos»}{ }^{27}$. En las Jornadas Feministas de diciembre de 2009 dijo, entre otras cosas, lo siguiente:

Hemos aprendido que la identidad de las mujeres es múltiple. No existe «la mujer», sino mujeres con intereses diversos, incluso contradictorios. Antes teníamos una especie de feministómetro para decidir quién era realmente feminista. Ahora con algunas mujeres puedes caminar tres kilómetros, con otras veinte y con otras cien, pero debemos ir juntas. Ese es el reto ${ }^{28}$.

El feminismo de la tercera ola recoge los frutos de la segunda ola, (y también de la primera), de las interpretaciones controvertidas, a veces, del feminismo de la igualdad y el feminismo de la diferencia, y de los debates que se generaron a lo largo de tres décadas por mujeres que no sólo soñaron sino que se movieron y lucharon por un mundo más igualitario, pero también con más libertad para ejercer las diferencias, para poder proclamarse mujer sin que ello significase quedar atada a ningún modelo prototípico. El debate entre los diversos feminismos hoy está saliendo de la lógica dualista del patriarcado, que es la que forzó ese dilema de la diferencia que había atenazado a las mujeres a elegir entre igualdad y diferencia. Después de mucho empeño, y un hermoso legado feminista, hoy sabemos que una y otra no sólo son compatibles, sino que en diálogo pueden apartarnos de la lógica que domina la institucionalización de la igualdad como un asunto de simples derechos y leyes ${ }^{29}$. Hoy sabemos que podemos querer más y mejor ${ }^{30}$.

27. Empar Pineda tildaba al feminismo de la diferencia de conservador y de falta de visión política. Véase PINEDA, Empar. «El mito de la feminidad cabalga de nuevo», en El viejo topo, número extra 10 (1980), pp. 19-22.

28. Palabras de Empar Pineda recogidas en la crónica de Mónica Ceberio Belaza publicada en el periódico «El País», en su edición impresa del domingo 13 de diciembre de 2009.

29. Cf. ZERILli, Linda, El feminismo y el abismo de la libertad, Op.cit., pp. 231-238.

30. Para un libro sugerente en este sentido véase BOCHETTI, Alessandra. Lo que quiere una mujer, Madrid, Cátedra-Instituto de la Mujer, 1996.

Feminismo/s 15, junio 2010, pp. 15-32 


\section{Referencias bibliográficas}

Bochetti, Alessandra. Lo que quiere una mujer, Madrid, Cátedra-Instituto de la Mujer, 1996.

BUTLER, Judith. «La cuestión de la transformación social», en Judith Butler, Elisabeth Beck-Gernsheim y Lídia Puigvert, Mujeres y transformaciones sociales, Barcelona, El Roure, 2001.

Collin, Françoise. «Una herencia sin testamento», en VV.AA. Feminismos fin de siglo. Una herencia sin testamento, especial Revista Fempress, Santiago de Chile, 1999.

Collin, François. Praxis de la diferencia. Liberación y libertad. Barcelona, Icaria, 2006 (edición de Marta Segarra).

CotT, Nancy F. The Grounding of Modern Feminism. New Haven, Yale University Press, 1987.

PINEDA, Empar. «El mito de la feminidad cabalga de nuevo», en El viejo topo, número extra 10 (1980), pp. 19-22

Hoff Sommers, Christina. Who Stole Feminism?: How Women Have Betrayed Women, Nueva York, Simon and Schuster, 1995.

Millett, Kate. Política sexual. Madrid, Cátedra-Instituto de la Mujer. Colección Feminismos, 1995 (traducción de Ana María Bravo García, revisada por Carmen Martínez Gimeno, y edición de Amparo Moreno).

MoI, Toril. What is a Woman? And Other Essays. Oxford University Press, 2000.

OFFEN, Karen. «Defining feminism: a comparative historical approach», en Gisela Bock y Susan James (eds.), Beyond Equality and Difference, London, Routledge, 1992, pp. 79-88.

OFFEN, Karen. «Feminism and sexual difference in historical perspective», en Deborah Rhode (ed.), Theoretical Perspectives on Sexual Difference, New Haven, Conn., Yale University Press, 1990, pp. 13-20.

Pateman, Carole. The disorder of Women. Cambridge, Polity Press, 1989.

ReVerter Bañón, Sonia. «El ruido de la teoría feminista». Cuadernos KÒRE, n.1 (2009), pp. 53-68.

ScotT, Joan. Only Paradoxes to Offer: French Feminists and the Rights of Man. Cambridge, Harvard University Press, 1996.

SKEGGS, Beverly. «The dirty history of feminism and sociology: or the war of conceptual attrition». The Sociological Review, 56:4 (2008), pp. 670-690.

TRUTH, Sojourner. «Ain't I a Woman». Feminist Theory: A Reader. 2nd Ed. Wendy Kolmar y Frances Bartowski (eds.), New York, McGraw-Hill, 2005, pp. 79.

Wollstonecraft, Mary. Vindicación de los derechos de la mujer. Madrid, CátedraInstituto de la Mujer, 1994 (traducción de Carmen Martínez Gimeno, y edición de Isabel Burdiel).

ZeriLli, Linda. El feminismo y el abismo de la libertad. Buenos Aires, Fondo de Cultura Económica, 2008 (traducción de Teresa Arijón). 